article/414/

3) Dunn EL, Moore EE, Moore JB. Hemodynamic effects of aortic occlusion during hemorrhagic shock. Ann Emerg Med. 1982;11:238-41.

4) Katz NM, Blackstone EH, Kirklin J, et al. Incremental risk factors for spinal cord injury following operation for acute traumatic aortic transection. J Thorac Cardiovasc Surg. 1981;81:669-74.

5) 石原 晋, 金子高太郎. 鈍的腹部外傷の出血制御を目的と した専用大動脈遮断カテーテルの臨床応用. 日外傷会誌. 1998;12:11-6.

6) 葛西 猛. 開腹法と術野の展開. 消化器外科. $2002 ; 25$ : 1525-9.

受付日 2008 年 2 月 17 日

採択日 2008 年 3 月 1 日

\section{Resuscitation strategy for exanguinating intraperitoneal hemorrhage, not respond- ing to initial fluid management, by an intra-aortic occlusion balloon catheter}

To the Editor: Akihide Konn

Department of Emergency and Critical Care Medicine, Hachinohe City Hospital

(1 Bishamontaira, Tamukai, Hachinohe, Aomori 031-8555, Japan)

J Jpn Soc Intensive Care Med. 2008;15:353 355.

\title{
鎮静スケールの使い方
}

\section{編集委員長殿}

筆者が鎮静スケールに興味を持ったのは，15年ほど 前であったように思う。それまでは, ICUにおける鎮 痛, 特に硬膜外鎮痛を中心に研究していた。痛みのス ケールとして, 初期にはsimple verbal rating scale （VRS）を使用した ${ }^{1) 〜 4) 。 V i s u a l ~ a n a l o g u e ~ s c a l e ~(V A S) ~}$ を使用するようになったのは, 1990年代の前半からで

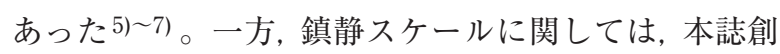
刊号 (1994年)に掲載された「集中治療における鎮静 疼痛管理の現状」という総説 ${ }^{8)}$ の中で, Ramsay鎮静ス ケールを紹介したが, 当時Ramsayスケールが現在の ように一般的な人工呼吸中の鎮静スケールになるとい う認識はあまりなかった。プロポフォールが本邦で発 売される以前であり, 人工呼吸患者の鎮静状態を細か く把握することに関心が向かなかったからかもしれな w。

ところが, 同年Critical Care Medicine (CCM) 誌に 揭載された「Beyond the Ramsay scale」を読んで, 目 からうろこが落ちた ${ }^{9)}$ 。本論説は, Ramsayスケール をICUにおける標準的な鎮静スケールと位置づけ，そ の問題点を明確にし，より優れた鎮静スケールを作る 必要があることを強調したすばらしい論文である。実 際, Ramsayスケールには, (1)アジテーション (不穏,
興奮, 体動) の程度を評価できない, (2)鎮静レベル間 の違いが不明確である, (3)至適鎮静レベルが示されて いない, (4)信頼性・妥当性が評価されていない, など の問題点がある。個人的には, Ramsayスケールは, 原著10)よりも本論説9)により有名になったと考えてい る。さらに, プロポフォールのような調節性の良い鎮 静薬の出現が, Ramsay鎮静スケールの必要性を高め たと考えられる11)。2001年に行ったICU看護師への アンケート調査において, Ramsayスケールはまだ一 般的ではなかったが, Ramsayスケールを使用してい る施設における看護師からの評価は高く12),13), 将来的 に一般的な鎮静スケールになると確信した。

$\lceil$ Beyond the Ramsay scale」以後, 次々と新しい 鎮静スケールが開発されたが, それらのほとんどは 「Beyond the Ramsay scale」をふまえて作られたもの と考えられる。本誌 15 巻 2 号に揭載された卯野木らの 論文は, Ramsayスケールと「Beyond the Ramsay scale」以後に開発された $3 つ の$ 鎮静スケール〔SedationAgitation Scale, Motor Activity Assessment Scale, Richmond Agitation-Sedation Scale (RASS)]につい て, その特徴, 信頼性・妥当性, 使いやすさなどを詳 細に検討した価值ある解説である14)。本論文は, 特に 
看護学分野からの報告であることに意義があると思わ れる。鎮静スケールによる評価は, ベッドサイドで患者 を観察する看護師にとって, バイタルサインと同様に重 要なものであり ${ }^{15)}$, 是非一読していただきたいと思う 次第である。

卯野木らの論文は, 鎮静スケールとしてRASSを推 奨しているが, これは最近, 日本呼吸療法医学会によ り作成された「人工呼吸中の鎮静のためのガイドライ ン」16) と一致している。RASSは, アジテーションを 十分に評価できることに加えて, confusion assessment method for the ICU (CAM-ICU) と組み合わせ ることにより, 人工呼吸患者のせん妄を評価すること が可能であるという利点を有する。今後は鎮静ばかり でなく, せん妄の評価が重要になってくると思われる。

鎮静スケールの使い方で問題になるのは, 疼痛の評 価である。前述の4つの鎮静スケールには痛みに関す る記載はないが, 術後患者や外傷患者は強い痛みを有 する可能性があり, これを除去しないとアジテーショ ンを生じる。このように人工呼吸中は痛みを評価する 必要があるが, 実際にはかなり難しい。VRSやVAS の使用は人工呼吸中は不可能なことも多い。表情, 体 動, 姿勢などの「ふるまいスケール」を用いるのが一般 的になりつつある17)。ふるまいスケールの中で, フェ イススケールは医師や看護師が患者の表情から痛みを 評価するものであるが, 筆者らは食道切除や肝切除術 後で検討し，有用であることを明らかにした 18),19)。 フェイススケールについての論文は, CCM 誌の鎮静ガ イドライン (2002年) 20)にも引用されたが, 間違って記 載されている。修正文を揭載してもらったが21), 誤解 している方がいるのではないかと憂慮している (「フェイススケールは, 中等度の疼痛では判定にばら つきが生じる」が正しい)。

本邦では, 鎮静と鎮痛を明確に分ける傾向があるが, 欧米では必ずしも区別していない。むしろ，重症患者 の鎮静には, 睡眠や鎮痛が含まれると考えられている。 最近のParkらの論文では,「睡眠を基本とする鎮静」 (ミダゾラムやプロポフォールを使用し, 必要に応じ て鎮痛薬を投与する一般的な方法）と「鎮痛を基本と する鎮静」（レミフェンタニルを用いて，必要時のみ 睡眠薬を投与する方法)に分け，後者は「容易に覚醒す るが, 痛みのない満足度の高い鎮静状態」を可能にす ると報告した ${ }^{22)}$ 。今後, 本邦でも調節性の良い鎮痛薬 が使用されるようになれば，鎮静の考え方や鎮静ス ケールの使い方が変わるかもしれない。

個々の患者の至適鎮静レベルを決定することは難し いが, 鎮静目標をしっかり決め, 鎮静過剩を避けるこ
とが重要である23)。そのため, RASSなどの適切な鎮 静スケールを使用することが推奨されている。最近は, 比較的浅い鎮静が患者の予後に好影響を与えるかもし れないと考えられている24),25)。

鎮静スケールは今後ますます重要になると思われ る。本邦のICUで働く医師, 看護師が使いやすい, 簡 便かつ, 信頼性・妥当性が高いスケールの開発が望ま れる。

\section{行岡 秀和}

行岡医学研究会行岡病院麻酔・救急・集中治療科

（=530-0021大阪府大阪市北区浮田 2-2-3）

\section{文 献}

1) 田中幸雄, 河崎 収, 行岡秀和, 他. 肝切除患者に対する 硬膜外モルヒネによる術後疼痛管理． ICU と CCU. 1985;9: 333-7.

2) 高田敏夫, 行岡秀和, 藤森 貢. 肝切除患者に対する硬膜 外モルヒネおよびブプレノルフィンによる術後疼痛管理. 麻酔. 1990;39:13-8.

3) Yukioka H, Fujimori M. Epidural opioids for postoperative pain relief following hepatectomy. Osaka City Med J. 1992;38:67-77.

4) Terai T, Yukioka H, Morimoto O, et al. Lumbar epidural buprenorphine for postoperative pain relief following hepatectomy. J Anesth. 1994;8:410-4.

5) 过井健二, 行岡秀和, 寺井岳三, 他. 硬膜外鎮痛下の食道 癌術後早期胸部理学療法の効果. ICU と CCU. 1996;20: 1041-5.

6) 寺井岳三, 行岡秀和, 藤井 崇, 他. 硬膜外モルヒネを用 いた肝切除術後痛管理における術中局所麻醉薬持続投与の 効果. 麻酔. 1997;46:100-4.

7) Terai T, Yukioka H, Fujimori M. Administration of epidural bupivacaine combined with epidural morphine after esophageal surgery. Surgery. 1997;121:359-65.

8) 行岡秀和. 集中治療における鎮静疼痛管理の現状. 日集中 医誌. 1994;1:13-9.

9) Hansen-Flaschen J, Cowen J, Polomano RC. Beyond the Ramsay scale: need for a validated measure of sedating drug efficacy in the intensive care unit. Crit Care Med. 1994;22:732-3.

10) Ramsay MAE, Savege TM, Simpson BRJ, et al. Controlled sedation with alphaxalone-alphadolone. Br Med J. 1974;2: 656-9.

11) 行岡秀和. 術後鎮静. ICU と CCU. 1998;22:241-6.

12) 行岡秀和, 栗田 聡, 吉田 玄, 他. ICU 看護師による鎮 痛・鎮静の評価と問題点 一鎮痛・鎮静スケール導入の有 用性. 日集中医誌. 2002;9:419-22.

13）行岡秀和, 栗田 聡, 吉田 玄, 他. ICU 看護師の鎮痛 · 鎮静についての認識と評価. 日集中医誌.2003;10:131-4.

14）卯野木健, 芹田晃道, 四本竜一. 成人 ICU患者に打いては どの鎮静スケールが有用か? 一文献を用いた 4 つの鎮静ス ケールの比較一。集中医誌. 2008;15:179-88.

15) Ramsay MAE. Measuring level of sedation in the intensive care unit. JAMA. 2000;284:441.

16) 妙中信之, 行岡秀和, 足羽孝子, 他. 人工呼吸中の鎮静の ためのガイドライン. 人工呼吸. 2007;24:146-67.

17）行岡秀和ＩCUに扔けるオピオイド，日臨麻会誌．2006; 
26:654-63.

18) Terai T, Yukioka H, Asada A. Pain evaluation in the intensive care unit: observer-reported faces scale compared with self-reported visual analog scale. Reg Anesth Pain Med. 1998;23:147-51.

19）寺井岳三, 行岡秀和. フェイススケールによる術後痛の評 価 一肝切除術と食道切除術の比較. 麻醉. 1999;48:981-5.

20) Jacobi J, Fraser GL, Coursin DB, et al. Clinical practice guidelines for the sustained use of sedatives and analgesics in the critically ill adult. Crit Care Med. 2002;30:119-41.

21) Yukioka H. Less agreement is noted between the visual analog scale and the faces scale for patients with moderate pain than for those with severe pain. Crit Care Med. 2003;31:2417-8.

22) Park G, Lane M, Rogers S, et al. A comparison of hypnotic and analgesic based sedation in a general intensive care unit. Br J Anaesth. 2007;98:76-82.

23) Fraser GL, Riker RR. Comfort without coma: changing sedation practices. Crit Care Med. 2007;35:635-7.

24) Schweickert WD, Gehlbach BK, Pohlman AS, et al. Daily interruption of sedative infusions and complications of critical illness in mechanically ventilated patients. Crit Care Med. 2004;32:1272-6.

25) Quenot JP, Ladoire S, Devoucoux F, et al. Effect of a nurse-implemented sedation protocol on the incidence of ventilator-associated pneumonia. Crit Care Med. 2007;35: 2031-6.

受付日2008年 2 月 26 日 採択日 2008 年 3 月 1 日

\section{How to use sedation scales in the ICU}

To the Editor: Hidekazu Yukioka

Department of Anesthesia, Emergency and Intensive Care, Yukioka Hospital

(2-2-3 Ukita, Kita-ku, Osaka, Osaka 530-0021, Japan)

J Jpn Soc Intensive Care Med. 2008;15:355 357.

\section{集中治療専門医の役割・位置づけ}

著者回答

私の発表した論文1)に長浜先生より貴重なコメン ト2)を頂き感謝申し上げる。長浜先生は, この論文を 指して「日本集中治療医学会を代表して会員に提言し ていると考えられる」と述べられているが，この論文 はあくまでも筆者が個人で論述したものであり，日本 集中治療医学会の専門医制度委員会で審議した結果で も，理事会で審議した結果でもない。私が第 35 回日本 集中治療医学会学術集会 (2008年, 東京) の会長を務 めさせて頂いたのでそのような印象を持たれたのかも しれないが, 日本集中治療医学会としての公式見解と は何の関係もなく，そのような記載も論文中には一切 ない。

「脳神経外科学会を基本的な診療科と考えられない 学会」との引用を問題にして, 私の論述が矛盾してい ると指摘して抢られる。これは, 私の論文中の「基本 領域の学会の中には, 脳神経外科学会, 救急医学会, 形成外科学会, リハビリテーション医学会など, 基本 的な診療科と考えられない学会が含まれている」とい
う第 III 次学術推進会議報告書「我が国に扔ける専門医 のあり方」3からの引用を指していると思われる。こ れは「個人的見解」ではなく, 既に本文でも述べたし, 私の論文1の中でも出典を明確に記載したように, 日 本医師会学術推進会議からの公式文書での見解であ る。この報告書の内容をどのように捉えるかは, 非常 に興味のある点であるが, この報告書が2006年に出 された後に多くの討論がなされたとは, 寊聞にして存 じ上げない。活発な討論を期待したいところである。

我々の持っている集中治療専門医制度は, 修業年限 のみは設けられているが, その内容に関してはカリ キュラムがない4)。徒弟制度のように一定年限修行し て試験に合格すればよい，というのではあまりに問題 が多いというのが私の主張である。先人の御尽力によ り我々は専門医制度を持つことができたが，その内容 の充実に取り組んできたのか, という問題提起に会員 の皆様には耪智を絞って頂けたら幸いである。多くの 努力を傾注して専門医制度を形作ってきたEuropean 